\title{
A New Ceramic Sr2Fe8018: Crystal Structure and Analysis of Application on Solid Electrolytes
}

\section{Zan Ren}

Beijing Information Science and Technology University - Jianxiangqiao Campus

Qingwei Liao ( $\sim$ liaoqingwei520@yahoo.com )

Beijing Information Science and Technology University

\section{Binglin Kang}

Beijing Information Science and Technology University - Jianxiangqiao Campus

\section{Kexuan Liao}

Tongji University

\section{Liyin Chen}

Harvard University

\section{Wenxiao Jiang}

Shenzhen University

\section{Lei Qin}

Beijing Information Science and Technology

\section{Likun Wang}

Beijing Information Science and Technology

\section{Research Article}

Keywords: Oxygen-deficient perovskite, Solid electrolyte, Crystal structure, Ion conductor

Posted Date: December 22nd, 2020

DOI: https://doi.org/10.21203/rs.3.rs-131868/v1

License: (c) (1) This work is licensed under a Creative Commons Attribution 4.0 International License. Read Full License 


\title{
A New Ceramic $\mathrm{Sr}_{2} \mathrm{Fe}_{8} \mathrm{O}_{18}$ : Crystal Structure and Analysis of Application on Solid Electrolytes
}

\author{
Zan Ren ${ }^{1}$, Qingwei Liao ${ }^{1 *}$, Binglin Kang ${ }^{1}$, Kexuan Liao ${ }^{2}$, Liyin Chen ${ }^{3}$, Wenxiao Jiang ${ }^{4}$, Lei Qin ${ }^{1}$, \\ Likun Wang ${ }^{1}$ \\ ${ }^{1}$ Key laboratory of sensors, Beijing Information Science \& Technology University, Beijing 100192, \\ China \\ ${ }^{2}$ School of Chemical Science and Engineering, Tongji University, Shanghai 200092, China \\ ${ }^{3}$ John A Paulson School of Engineering and Applied Sciences, Harvard University, Cambridge, MA, \\ 02138, USA \\ ${ }^{4}$ School of Basic Medical Sciences, Shenzhen University Health Sciences Center, Shenzhen 518060, \\ China
}

* Corresponding author, Qingwei Liao E-mail: liaoqingwei520@yahoo.com, Tel: 0086-10-64886473; Kexuan Liao E-mail: leon_kx@163.com, Tel: 0086-10-64886473; Lei Qin E-mail: qinlei@bistu.edu.cn, Tel: 0086-10-64886473.

Abstract: All-solid-state batteries have been expected to overcome the safety problem of present lithiumion batteries including organic liquid electrolytes. The materials with high ionic conductivity are urgently needed. In this paper, we reported a new ionic crystal $\mathrm{Sr}_{2} \mathrm{Fe}_{8} \mathrm{O}_{18}$ which can be applicated on solid electrolyte. $\mathrm{Sr}_{2} \mathrm{Fe}_{8} \mathrm{O}_{18}$ is a typical p-type semiconductor and shows a layered monoclinic crystal structure. The resistivities of $\mathrm{Sr}_{2} \mathrm{Fe}_{8} \mathrm{O}_{18}$ in the temperature range of $20 \sim 145^{\circ} \mathrm{C}$ were above $10^{7} \Omega \bullet \mathrm{cm}$. The microstructure of $\mathrm{Sr}_{2} \mathrm{Fe}_{8} \mathrm{O}_{18}$ was flaky, and the size of flaks were $1 \mu \mathrm{m} \sim 5 \mu \mathrm{m}$. The $E$ - $P$ curve suggested that it was a ferroelectric semiconductor and had small ferroelectric effect. The dielectric response study (Cole-Cole plot) showed that $\mathrm{Sr}_{2} \mathrm{Fe}_{8} \mathrm{O}_{18}$ had two separated relaxation time, each of which contained a group of relaxation. The ionic conductivity $\sigma$ of the sample was calculated to be $0.2196 \times 10^{-4} \mathrm{~S} / \mathrm{cm}$. The conductive mechanism which confirmed by the results of First principle calculation at $300 \mathrm{~K}$ is mainly sublattice vacancy cation diffusion with self-diffusion coefficient D of $1.794 \times 10^{-5} \mathrm{~cm}^{2} / \mathrm{s}$. Fe ion has two dimensional diffusion path ( $\mathrm{x}$ and $\mathrm{y}$ axial), and $\mathrm{Sr}$ ion has on dimensional diffusion path (x axial). The crystal structure of $\mathrm{Sr}_{2} \mathrm{Fe}_{8} \mathrm{O}_{18}$ shows tremendous potential application on the solid electrolyte preparation.

Keywords: Oxygen-deficient perovskite; Solid electrolyte; Crystal structure; Ion conductor

\section{Introduction}


Current commercial lithium-ion batteries use combustible organic liquid electrolytes and thus suffer from fire risks during overcharge or abused operations, especially in large-scale applications [1-3]. Getting solid is the most important study point in the secondary battery research area. However, the development of solid-state batteries was has largely been hindered by the availability of solid electrolytes with fast ion conductivity. Therefore, the materials with high ionic conductivity are urgently needed for the development of solid-state secondary batteries. Up to now, solid electrolytes containing $\mathrm{Li}$ ion has attracted extensive research[4-16], while the reports about other solid electrolytes were rare. The Brownmillerite $\mathrm{Sr}_{2} \mathrm{Fe}_{2} \mathrm{O}_{5}$, which belongs to the oxygen-deficient perovskite family, has earned much attention because it has many interesting physical properties, such as being ion conducting, ferroelectric, ferromagnetic etc. [17-19]. Due to its special crystal structure, there were abundant research about structural characterization of oxygen-deficient perovskites [20-24]. The latest report about $\mathrm{Ca}_{2} \mathrm{Fe}_{0.5} \mathrm{Ga}_{1.5} \mathrm{O}_{5}$ by Hona et al. [25] pointed out that in oxygen deficient perovskites, the B-site cations usually form $\mathrm{BO}_{6}, \mathrm{BO}_{5}$, or $\mathrm{BO}_{4}$ polyhedral depending on the structure, while the A-site cations reside in spaces between the polyhedral. Changes in the A or B-site cations in oxygen-deficient perovskites can change crystal structures and lead to significant differences in electrical properties. This characteristic of oxygen-deficient perovskites indicates enormous potential in applications of sensing, solid-oxide fuel cells, and electrocatalysts.

Among all research of oxygen-deficient perovskites, materials with 1:1 atom proportion of $\mathrm{Sr}$ to $\mathrm{Fe}$ (or A-site to B-site) significantly outnumbered those with other atom proportions of $\mathrm{Sr}$ to $\mathrm{Fe}$, such as that in $\mathrm{Sr}_{4} \mathrm{Fe}_{6} \mathrm{O}_{13}$. We are interested in finding new material based on Brownmillerite and exploring better properties. Therefore, in this paper, we reported a new compound $\mathrm{Sr}_{2} \mathrm{Fe}_{8} \mathrm{O}_{18}$ with high ionic conductivity which have an atom proportion of $\mathrm{Sr}: \mathrm{Fe}=1: 4$. The crystal material, electronic structure, and the basic 
electrical properties (ferroelectricity, dielectric response, and ionic conductivity) were studied. The analysis of conductive mechanism of $\mathrm{Sr}_{2} \mathrm{Fe}_{8} \mathrm{O}_{18}$ indicated that the crystal structure of $\mathrm{Sr}_{2} \mathrm{Fe}_{8} \mathrm{O}_{18}$ shows tremendous potential application on the solid electrolyte preparation.

\section{Experimental section}

The $\mathrm{Sr}_{2} \mathrm{Fe}_{8} \mathrm{O}_{18}$ ceramic was synthesized directly by pure $\mathrm{SrCO}_{3}(>99.9 \%)$ and $\mathrm{Fe}_{2} \mathrm{O}_{3}(>99.9 \%)$ powders via solid-state method. The mixed powders were pressed into pellets after $24 \mathrm{~h}$ ball milling, and sintered at $1220^{\circ} \mathrm{C}$ for $3 \mathrm{~h}$. The phase structure were examined by X-ray diffraction (XRD) in the $2 \theta$ range of 20 - $50^{\circ}$ with a step size of $0.02^{\circ}$ using the Bruker D8 advance at $40 \mathrm{kV} / 40 \mathrm{~mA}$ with $\mathrm{Cu} \mathrm{K} \alpha$ radiation ( $\lambda=0.154 \mathrm{~nm})$. The polished samples after thermal etching were prepared and observed using a Scanning Electron Microscope (JSM-6510-LV, JEOL, Japan). The ceramic pellets for electrical characterization were polished and coated with silver electrodes. The resistivities were measured using an Keithley digital multimeter (DMM7510 7 1/2, United States) from room temperature to $435^{\circ} \mathrm{C}$. The polarization-electric field hysteresis loops were measured with a Precision LC ferroelectric test system (Radiant Technologies, Northford, United States) at room temperature. EIS (Electrochemical Impedance Spectroscopy) was carried out using electrochemical workstation measurement system in the frequency range of $0.1 \mathrm{~Hz}$ to $100 \mathrm{kHz}$

\section{Results and Discussions}

The XRD patterns of the $\mathrm{Sr}_{2} \mathrm{Fe}_{8} \mathrm{O}_{18}$ sample is shown in Fig.1 (a). The sample shows a monoclinic structure (space group: $P_{121}$ ) with $a=8.4009 \AA, b=8.4623 \AA, c=6.4648 \AA, \beta=111.676$, and $V_{\text {cell }}=427.09$ $\AA^{3}$. The crystal structure was calculated and refined [26] with $R$ factor of $R_{\mathrm{p}}=5.81, R_{\mathrm{wp}}=7.39, R_{\mathrm{e}}=5.42$, $C h i^{2}=1.86$, and the parameter detail of crystal structure was shown in Table 1. Fig. 1 (b) (e) shows the graphical results of refinement and the detail of crystal structure of $\mathrm{Sr}_{2} \mathrm{Fe}_{8} \mathrm{O}_{18}$. Fig. 1 (b) shows the 
graphical results of refinement. Fig. 2 (c) (e) show the detail of crystal structure of $\mathrm{Sr}_{2} \mathrm{Fe}_{8} \mathrm{O}_{18}$. There were two molecules in one unit cell, in other words, $\mathrm{Z}=2$. The whole structure composed by layered $\mathrm{FeO}_{6}$ and the $\mathrm{FeO}_{6}$ was a distorted oxygen octahedrons. Every four $\mathrm{FeO}_{6}$ was a repetitive unit, where three of them were connected by edge and one by angle. $\mathrm{Sr}_{2} \mathrm{Fe}_{8} \mathrm{O}_{18}$ has excess oxygen ions, therefore, it has many cation vacancy, shows character of p-type semiconductor. Those cation vacancy provides the possibility for sublattice vacancy cation diffusion which shows ionic conduction macroscopically. Furthermore, the geometry of crystal structure had been optimization by First principle calculation. Fig. 2 shows the relative results of First principle calculation [27-30] and the resistivities of $\mathrm{Sr}_{2} \mathrm{Fe}_{8} \mathrm{O}_{18}$ in the temperature range of room temperature to $435^{\circ} \mathrm{C}$. Fig. 2 (a) shows the energy optimizing results during the last time of geometry optimization. The geometry optimization was taken twice. The plane wave basis set cut-off of the first time was $340 \mathrm{eV}$ with the function of GGA by Perdew, Burke and Ernzerhof [31], and the energy decreased from about $-16380 \mathrm{eV}$ to $-16440 \mathrm{eV}$. The plane wave basis set cut-off of the second time was $340 \mathrm{eV}$ with the function of GGA by Perdew-Wang 1991 (PW91) [32], and the energy decreased from about $-16440 \mathrm{eV}$ to $-16470 \mathrm{eV}$. Fig. 2 (b) $\sim$ (e) shows the final crystal structure after geometry optimization. The whole structure is composed by $\mathrm{FeO}_{4}$ which is connected by angle and $\mathrm{SrO}_{6}$ which is connected by edge. Every three $\mathrm{FeO}_{4}$ that are connected by $\mathrm{O}_{1}$ is a repeat unit, and every repeat unit is connected by $\mathrm{O}_{5}$. Fig. 2 (f) shows the resistivity of $\mathrm{Sr}_{2} \mathrm{Fe}_{8} \mathrm{O}_{18}$ in the temperature range of room temperature to $435^{\circ} \mathrm{C}$. It was the typical resistivity characteristic of semiconductor, and the relative relationship between resistivity and temperature was:

$$
\rho=\rho_{0} e^{-\alpha T}
$$

where $\rho_{0}$ is the resistivity in room temperature; $\rho$ is the resistivity; $T$ is the temperature; $\alpha$ is the temperature coefficient of resistivity, the $\alpha$ could be calculated. In this study, the $\alpha$ of $\mathrm{Sr}_{2} \mathrm{Fe}_{8} \mathrm{O}_{18}$ was - 
0.02334. The insulating property is important to solid electrolyte. Therefore, the resistivities in the temperature range of $20 \sim 145^{\circ} \mathrm{C}$ are shown in the inset of Fig. 2 (f). The resistivities of $\mathrm{Sr}_{2} \mathrm{Fe}_{8} \mathrm{O}_{18}$ in the temperature range of $20 \sim 145^{\circ} \mathrm{C}$ were from $1.5556 \times 10^{8}$ to $1.1227 \times 10^{7} \Omega \bullet \mathrm{cm}$, respectively.

Fig. 3 shows the $\mathrm{SEM}$ photograph of $\mathrm{Sr}_{2} \mathrm{Fe}_{8} \mathrm{O}_{18}$ sample. In the first sight, the $\mathrm{Sr}_{2} \mathrm{Fe}_{8} \mathrm{O}_{18}$ ceramic composed by granule microstructure. But take a good look at the photograph, every granule was actually layered. Therefore, it also can be seen form the zoom-in picture on the right side, the microstructure of $\mathrm{Sr}_{2} \mathrm{Fe}_{8} \mathrm{O}_{18}$ was flaky, and the size of flaks were $1 \mu \mathrm{m} \sim 5 \mu \mathrm{m}$. In view of this feature, $\mathrm{Sr}_{2} \mathrm{Fe}_{8} \mathrm{O}_{18}$ might have the potential applications in the area of energy storage and conversion [33-36].

Fig. 4 shows the dielectric and ferroelectric properties of $\mathrm{Sr}_{2} \mathrm{Fe}_{8} \mathrm{O}_{18}$ samples. Fig. 4 (a) shows the Polarization Electric field (P-E) hysteresis loops of the $\mathrm{Sr}_{2} \mathrm{Fe}_{8} \mathrm{O}_{18}$ samples tested at room temperature. The largest voltage which $\mathrm{Sr}_{2} \mathrm{Fe}_{8} \mathrm{O}_{18}$ sample (thickness $d=0.75 \mathrm{~mm}$ ) can bear was $2 \mathrm{kV}$. The whole loops show the anomalous hysteresis phenomena. The polarization was keeping increase for a period during the decrease of voltage. J. Wei et al. [37] once reported a model of P-E loop, as shown in the formula below:

$$
\begin{gathered}
\text { from }-\mathrm{V}_{\max } \text { to } \mathrm{V}_{\max }, \mathrm{Q}_{\mathrm{T}}=\mathrm{cV}+\frac{V^{2}}{2 R A}+\mathrm{Q}_{\mathrm{F}} \approx \mathrm{cV}+\frac{V^{2}}{2 R} \frac{\Delta t}{|\Delta V|}+\mathrm{Q}_{\mathrm{F}} \\
\text { from } \mathrm{V}_{\max } \text { to }-\mathrm{V}_{\max }, \mathrm{Q}_{\mathrm{T}}=\mathrm{cV}+\frac{V_{\max }^{2}}{R A}-\frac{V^{2}}{2 R A}+\mathrm{Q}_{\mathrm{F}} \approx \mathrm{cV}+\left(\frac{V_{\text {max }}^{2}}{R}-\frac{V^{2}}{2 R A}\right) \frac{\Delta t}{|\Delta V|}+\mathrm{Q}_{\mathrm{F}}
\end{gathered}
$$

where $c$ is the capacitance; $V$ is the bias voltage, $Q_{\mathrm{F}}$ which is here can be expressed as polarization $P$ (stands for the polarization intensity), is caused by ferroelectric effect, and is the polarized charge quantity nonlinear to $V ; R$ is the resistance of the conductive layer, $\Delta V / \Delta t$ is the scan velocity of $V, A$ is the scan speed of voltage, and $Q_{\mathrm{T}}$ is the total charge quantity. If $Q_{\mathrm{F}}$ is negligible, in other words, the material don't have obvious ferroelectric effect, the $Q_{\mathrm{T}}-E$ curve will be parabolic, like the Fig. 1 (c ) in the ref. 37. Therefore, the $E$ - $P$ curve of $\mathrm{Sr}_{2} \mathrm{Fe}_{8} \mathrm{O}_{18}$ suggested that it was a ferroelectric semiconductor 
which do showed the ferroelectric effect but was smaller than the traditional one. The remanent polarization $P_{\mathrm{r}}$ was around $0.1737 \mu \mathrm{C} / \mathrm{cm}^{2}$, and the coercive field $E_{\mathrm{c}}$ was around $1.9309 \mathrm{kV} / \mathrm{cm}$. The dielectric spectroscopy shows the dynamical dielectric, which is important for discussing the physical properties of ionic crystal material at the molecular level. Fig. 4 (b) and (c) show the dielectric response of frequency and the Cole-Cole plot [38] of $\mathrm{Sr}_{2} \mathrm{Fe}_{8} \mathrm{O}_{18}$, respectively. Fig. 46 (a) shows the dielectric response of frequency (form $40 \mathrm{~Hz}$ to $110 \mathrm{MHz}$ ) of $\mathrm{Sr}_{2} \mathrm{Fe}_{8} \mathrm{O}_{18}$. The pink area is the relaxation rang of $\mathrm{Sr}_{2} \mathrm{Fe}_{8} \mathrm{O}_{18}$. The $\varepsilon^{\prime}$ (the real part of the complex dielectric constant) decrease with increase of frequency, and the $\varepsilon^{\prime \prime}$ (the imaginary part of the complex dielectric constant) first increase and then decrease with increase of frequency. Thus, the $\varepsilon^{\prime \prime}$ has the maximum value, and at this point of frequency, there is a following relationship:

$$
\omega \tau=\sqrt{\frac{\varepsilon_{s}}{\varepsilon_{\infty}}}
$$

where $\omega$ is the frequency; $\tau$ is the relaxation time; $\varepsilon_{s}$ is the shunt dielectric constant; $\varepsilon_{\infty}$ is the dielectric constant at infinity frequency. Therefore, the relaxation time could be calculated via this relationship, and the value of relaxation time $\tau$ was $0.6007 \times 10^{-7}$. Fig. 4 (b) shows the Cole-Cole plot from the data of Fig. 4 (a). It can be seen that $\mathrm{Sr}_{2} \mathrm{Fe}_{8} \mathrm{O}_{18}$ had two separated relaxation time, and each one contained a group of relaxation. As previous report, the first group relaxation times were from grain, and the second group were from grain boundary.

Fig. 5 shows a typical impedance plot obtained at room temperature for a $\mathrm{Sr}_{2} \mathrm{Fe}_{8} \mathrm{O}_{18}$ sample with thickness of $1 \mathrm{~mm}$ and sectional area of $0.1 \mathrm{~cm}^{2}$. Fig. 5 (a) shows the Nyquist plot and the fitting curve with the equivalent circuit shown in Fig. 5 (b). According to the test method described at experiment, the equivalent circuit could be shown as Fig. $5(\mathrm{~b}) . R_{\mathrm{b}}$ is the resistance of solid electrolyte; $V_{\text {oigt }}$ component composed by $C_{\mathrm{bi}}$ and $R_{\mathrm{bi}}$ is the interface impedance between solid electrolyte and electrode; $V_{\text {oigt }}$ 
component composed by $C_{\mathrm{be}}$ and $R_{\mathrm{be}}$ is the interface impedance between solid electrolyte and liquid electrolyte; $R_{\mathrm{e}}$ is the resistance of liquid electrolyte; $V_{\mathrm{oigt}}$ component composed by $C_{\mathrm{ei}}, R_{\mathrm{ei}}$ and $Z_{\mathrm{w}}$ is the interface impedance between liquid electrolyte and electrode; $Z_{\mathrm{w}}$ is the Warburg impedance. After fitting with equivalent circuit the $R_{\mathrm{b}}, R_{\mathrm{bi}}, R_{\mathrm{be}}, R_{\mathrm{e}}$, and $R_{\mathrm{ei}}$ of $0.4554,0.1927,1292,0.5453,0.0645 \mathrm{M} \Omega$ were obtained, respectively. The ionic conductivity of the sample was calculated by the following formula:

$$
\sigma=\frac{\mathrm{L}}{\mathrm{R} \times \mathrm{S}}=\frac{\mathrm{L}}{R_{b} \times \mathrm{S}}
$$

where: $L$ is the sample thickness, $S$ is the sample area, $R$ is the sample resistance. The ionic conductivity $\sigma$ of the sample was calculated to be $0.2196 \times 10^{-4} \mathrm{~S} / \mathrm{cm}$

Analysis of application on solid electrolytes for $\mathrm{Sr}_{2} \mathrm{Fe}_{8} \mathrm{O}_{18}$ was shown in Fig. 6. Fig. 6 (c) shows the velocity autocorrelation function (VACF) from Molecular Dynamics (MD) calculation of $\mathrm{Sr}_{2} \mathrm{Fe}_{8} \mathrm{O}_{18}$ at $300 \mathrm{~K}$. It is known that the self-diffusion coefficient D can be calculated from VACF by the following function[39]:,

$$
\mathrm{D}=\frac{1}{3} \int_{0}^{\infty}\langle v(t) \cdot v(0)\rangle d t
$$

Where $v(0)$ and $v(\mathrm{t})$ are the initial particle velocity and at time t, respectively. $\langle v(t) \cdot v(0)\rangle$ is the value of VACF. Therefore, the cation self-diffusion coefficient of $\mathrm{Sr}_{2} \mathrm{Fe}_{8} \mathrm{O}_{18}$ can be calculated as $1.794 \times 10^{-}$ ${ }^{5} \mathrm{~cm}^{2} / \mathrm{s}$. Fig. 6(b) (d) show the cation diffusion velocities on the (100), (001), and (010) direction, respectively. It can be seen that on the (001) direction, there were three position had zero velocity which means there were no cation diffusion path on the (001) direction. There were different cation diffusion velocity distributed on the (100) and (010) direction. It was indicated that ion diffusion path existed in both (100) and (010) direction. The highest diffusion velocity on (100) and (010) direction were $3.62 \times 10^{4} \mathrm{~cm} / \mathrm{s}$, and $4.76 \times 10^{4} \mathrm{~cm} / \mathrm{s}$, respectively. The average diffusion velocity on (100) and $(010)$ 
direction were $1.98 \times 10^{4} \mathrm{~cm} / \mathrm{s}$ and $2.21 \times 10^{4} \mathrm{~cm} / \mathrm{s}$, respectively. Therefore, $(010)$ direction (y axis direction) had the higher ion diffusion velocity. This result can be analysis through crystal structure of $\mathrm{Sr}_{2} \mathrm{Fe}_{8} \mathrm{O}_{18}$. There are three ion diffusion mechanism in the ionic crystal: (1) vacancy diffusion; (2) interstitial diffusion; (3) sublattice diffusion. The sublattice diffusion has the lowest diffusion activation energy and the fastest diffusion velocity. The interstitial diffusion has the highest diffusion activation energy and hard to proceed. As discussed before, the intrinsic cation vacancy in $\mathrm{Sr}_{2} \mathrm{Fe}_{8} \mathrm{O}_{18}$ structure provides the possibility for sublattice vacancy cation diffusion. Both $\mathrm{FeO}_{4}$ and $\mathrm{SrO}_{6}$ were connected in the (010) direction, providing the diffusion path along the (010) direction for $\mathrm{Fe}$ ion and $\mathrm{Sr}$ ion. $\mathrm{Both}^{\mathrm{FeO}} 4$ and

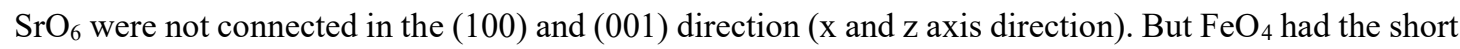
interval along the (100) direction, providing the possibility for Fe ion diffusion along the (100) direction. However, this diffusion had the higher diffusion activation energy than the sublattice diffusion. Therefore, (010) direction had the higher ion diffusion velocity than the (100) direction. Fig. 6 (e) $\sim$ (h) show the schematic diagram of ion diffusion path. Fe ion had the two-dimension diffusion path on both (100) and (010) direction (x and y axis direction). Sr ion had the one-dimension diffusion path on (010) direction (y axis direction).

\section{Conclusions}

In summary, a new oxygen-deficient perovskite compound $\mathrm{Sr}_{2} \mathrm{Fe}_{8} \mathrm{O}_{18}$ which can be a promising solid electrolyte, its microstructure and its physical properties were reported for the first time. It shows a layered monoclinic crystal structure with $\mathrm{a}=8.4009 \AA, \mathrm{b}=8.4623 \AA, \mathrm{c}=6.4648 \AA, \beta=111.676$, and $\mathrm{V}_{\text {cell }}=427.09 \AA^{3}$. The resistivities of $\mathrm{Sr}_{2} \mathrm{Fe}_{8} \mathrm{O}_{18}$ in the temperature range of $20 \sim 145^{\circ} \mathrm{C}$ are from $10^{8}$ to $10^{7}$ $\Omega \bullet \mathrm{cm}$. The microstructure of $\mathrm{Sr}_{2} \mathrm{Fe}_{8} \mathrm{O}_{18}$ was flaky with the size of $1 \mu \mathrm{m} \sim 5 \mu \mathrm{m}$. The $E-P$ curve results indicated that $\mathrm{Sr}_{2} \mathrm{Fe}_{8} \mathrm{O}_{18}$ was a ferroelectric semiconductor. The Cole-Cole plot showed that $\mathrm{Sr}_{2} \mathrm{Fe}_{8} \mathrm{O}_{18}$ 
had two separated relaxation time, and each one contained a group of relaxation. $\mathrm{Sr}_{2} \mathrm{Fe}_{8} \mathrm{O}_{18}$ has a large ionic conductivity $\sigma$ with value of $0.2196 \times 10^{-4} \mathrm{~S} / \mathrm{cm}$. The conductive mechanism is mainly sublattice vacancy cation diffusion with self-diffusion coefficient D of $1.794 \times 10^{-5} \mathrm{~cm}^{2} / \mathrm{s}$. Fe ion has two dimensional diffusion path (x and y axial), and $\mathrm{Sr}$ ion has on dimensional diffusion path (x axial).

\section{Acknowledgements}

This work was supported by the National Natural Science Foundation of China (No. 61871043), Beijing

Municipal Education Commission Science and Technology Plan Project (No. KM201811232021) and

Science and Technology Planning Project of Guangdong Province, China (No. 2017B020207009).

\section{Reference:}

1. J. Janek, W.G. Zeier, A solid future for battery development, Nature Energy. 1 (9) (2016) 16141. https://doi.org/10.1038/nenergy.2016.141.

2. Y. S. Hu. Batteries: Getting solid, Nature Energy. 1 (4) (2016) 16042. https://doi.org/10.1038/nenergy.2016.42.

3. B. John, Goodenough, Rechargeable batteries: challenges old and new, Journal of Solid State Electrochemistry. 16 (6) (2012) 2019-2029. https://doi.org/10.1007/s10008-012-1751-2.

4. M. Kotobuki, H. Munakata, K. Kanamura, Y. Sato, T. Yoshida, Compatibility of $\mathrm{Li}_{7} \mathrm{La}_{3} \mathrm{Zr}_{2} \mathrm{O}_{12}$ Solid Electrolyte to All-Solid-State Battery Using Li Metal Anode, J. Electrochem. Soc. 157 (10) (2010) 1076-1079. http://dx.doi.org/10.1149/1.3474232.

5. C. A. Geiger, E. Alekseev, B. Lazic, M. Fisch, T. Armbruster, R. Langner, et al,. Crystal chemistry and stability of " $\mathrm{Li}_{7} \mathrm{La}_{3} \mathrm{Zr}_{2} \mathrm{O}_{12}$ " garnet: a fast lithium-ion conductor. Inorganic Chemistry, 42(13) (2015), 1089-1097. https://doi.org/10.1002/chin.201113005.

6. M. Huang, T. Liu, Y. Deng, H.X. Geng, Y. Shen, Y.H. Lin, C.W. Nan, Effect of sintering temperature on structure and ionic conductivity of $\mathrm{Li}_{7}-\mathrm{xLa}_{3} \mathrm{Zr}_{2} \mathrm{O}_{12}-0.5 \mathrm{x}(\mathrm{x}=0.5 \sim 0.7)$ ceramics, Solid State Ionics, 204-205 (2011) 41-45. https://doi.org/10.1016/j.ssi.2011.10.003.

7. M. Kotobuki, K. Kanamura, Y. Sato, K. Yamamoto, T. Yoshida, Electrochemical properties of $\mathrm{Li}_{7} \mathrm{La}_{3} \mathrm{Zr}_{2} \mathrm{O}_{12}$ solid electrolyte prepared in argon atmosphere, Journal of Power Sources, 199 (2012) 346-349. https://doi.org/10.1016/j.jpowsour.2011.10.060.

8. F. Han , Y. Zhu , X. He , Y. Mo, C. Wang, Electrochemical Stability of Li10GeP2S12 and $\mathrm{Li}_{7} \mathrm{La}_{3} \mathrm{Zr}_{2} \mathrm{O}_{12}$ Solid Electrolytes, Advanced Energy Materials, 6(8) (2016) 1501590. https://doi.org/10.1002/aenm.201501590.

9. M. Kotobuki, K. Kanamura, Y. Sato, T. Yoshida, Fabrication of all-solid-state lithium battery 
with lithium metal anode using $\mathrm{Al}_{2} \mathrm{O}_{3}$-added $\mathrm{Li}_{7} \mathrm{La}_{3} \mathrm{Zr}_{2} \mathrm{O}_{12}$ solid electrolyte. Journal of Power Sources, 196 (18) (2011) 7750-7754. https://doi.org/10.1016/j.jpowsour.2011.04.047.

10. R. Murugan, V. Thangadurai, W. Weppner, Fast lithium ion conduction in garnet-type $\mathrm{Li}_{7} \mathrm{La}_{3} \mathrm{Zr}_{2} \mathrm{O}_{12}$. Angewandte Chemie, $46 \quad$ (2007) 7778-7781. https://doi.org/10.1002/anie.200701144.

11. S. Kumazaki, Y. Iriyama, K. H. Kim, R. Murugan, K. Tanabe, K. Yamamoto, et al, High lithium ion conductive $\mathrm{Li}_{7} \mathrm{La}_{3} \mathrm{Zr}_{2} \mathrm{O}_{12}$ by inclusion of both $\mathrm{Al}$ and $\mathrm{Si}$. Electrochemistry Communications, 13 (5) (2011) 509-512. https://doi.org/10.1016/j.elecom.2011.02.035.

12. D. Andre, A. Kuhn, L. Robben, M. Wilkening, P. Heitjans, Mechanosynthesis of solid electrolytes-preparation, characterization, and $\mathrm{Li}$ ion transport properties of garnet-type aldoped $\mathrm{Li}_{7} \mathrm{La}_{3} \mathrm{Zr}_{2} \mathrm{O}_{12}$ crystallizing with cubic. Journal of Physical Chemistry C, 116 (29) (2012) 15192. https://doi.org/10.1021/jp301193r.

13. I. Kokal, M. Somer, P.H.L. Notten, H.T. Hintzen. Sol-gel synthesis and lithium ion conductivity of $\mathrm{Li}_{7} \mathrm{La}_{3} \mathrm{Zr}_{2} \mathrm{O}_{12}$ with garnet-related type structures. Solid State Ionics, 185 (1) (2011) 42-46. https://doi.org/10.1016/j.ssi.2011.01.002.

14. E. Rangasamy, J. Wolfenstine, J. Sakamoto, The role of Al and Li concentration on the formation of cubic garnet solid electrolyte of nominal composition $\mathrm{Li}_{7} \mathrm{La}_{3} \mathrm{Zr}_{2} \mathrm{O}_{12}$. Solid State Ionics, Diffusion \& Reactions, 206 (2012) 28-32. https://doi.org/10.1016/j.ssi.2011.10.022.

15. S. Wenzel,S. Randau, T. Leichtweiss, D.A. Weber, J. Sann, W. G. Zeier, J. Janek. Direct observation of the interfacial instabilityof the fast ionic conductor $\mathrm{Li}_{10} \mathrm{GeP}_{2} \mathrm{~S}_{12}$ at the lithium metal anode. Chemistry of Materials, 28 (7) (2016) 2400-2407. https://doi.org/10.1021/acs.chemmater.6b00610.

16. G. Oh, M. Hirayama, O. Kwon, K. Suzuki, R. Kanno, Bulk-type all solid-state batteries with 5 v LiNiMnO cathode and LiGePS solid electrolyte. Chemistry of Materials, 28 (8) (2016), 26342640. https://doi.org/10.1021/acs.chemmater.5b04940.

17. C. A. J. Fisher, M. S. Islamb, Mixed ionic/electronic conductors $\mathrm{Sr}_{2} \mathrm{Fe}_{2} \mathrm{O}_{5}$ and $\mathrm{Sr}_{4} \mathrm{Fe}_{6} \mathrm{O}_{13}$ : atomic-scale studies of defects and ion migration, Journal of Materials Chemistry, 15(2005) 3200-3207. http://dx.doi.org/10.1039/b418567f.

18. A. Maity, R. Dutta, B. Penkala, M. Ceretti, A. Letrouitlebranchu, D. Chernyshov, et al, Solidstate reactivity explored in situ by synchrotron radiation on single crystals: from $\mathrm{SrFeO}_{2.5}$ to $\mathrm{SrFeO}_{3}$ via electrochemical oxygen intercalation. Journal of Physics D Applied Physics, 48 (50) (2015) 504004. http://dx.doi.org/10.1088/0022-3727/48/50/504004.

19. F. Zhu, Y. Wu, X. Lai, S. Qin, Y. Ke, Experimental and theoretical investigations on highpressure phase transition of $\mathrm{Sr}_{2} \mathrm{~F}_{2} \mathrm{O}_{5}$. Physics \& Chemistry of Minerals, 41 (6) (2014), 449-459. https://doi.org/10.1007/s00269-013-0604-6.

20. P. Lavela, J.L. Tirado, $\mathrm{CoFe}_{2} \mathrm{O}_{4}$ and $\mathrm{NiFe}_{2} \mathrm{O}_{4}$ synthesized by sol-gel procedures for their use as anode materials for Li ion batteries. Journal of Power Sources, 172 (1) (2007) 379-387. https://doi.org/10.1016/j.jpowsour.2007.07.055.

21. I. A. Leonidov, M. V. Patrakeev, J. A. Bahteeva, K. V. Poholok, D. S. Filimonov, K. R. Poeppelmeier, V. L. Kozhevnikov. Oxygen-ion and electron conductivity in $\mathrm{Sr}_{2}\left(\mathrm{Fe}_{1-\mathrm{x}} \mathrm{Ga}_{\mathrm{x}}\right)_{2} \mathrm{O}_{5}$, Journal of Solid State Chemistry, 179 (10) (2006) 3045-3051. https://doi.org/10.1016/j.jssc.2006.05.028. 
22. R.M. Pinacca, M.C. Viola, J.C. Pedregosa, M.J. Martínez-Lope, R.E. Carbonio, J.A. Alonso, Preparation, crystal structure and magnetic behavior of new double perovskites $\mathrm{Sr}_{2} \mathrm{~B}^{\prime} \mathrm{UO}_{6}$ with $\mathrm{B}^{\prime}=\mathrm{Mn}, \mathrm{Fe}, \mathrm{Ni}, \mathrm{Zn}$, Journal of Solid State Chemistry, 180 (5) (2007) 1582-1589. https://doi.org/10.1016/j.jssc.2007.03.002.

23. N. Kumar, G. Khurana, A. Gaur, R.K. Kotnala, Room temperature low field magnetoresistance in $\mathrm{Sr}_{2} \mathrm{FeMoO}_{6} / \mathrm{Zn}_{\mathrm{x}} \mathrm{Fe}_{1-\mathrm{x}} \mathrm{Fe}_{2} \mathrm{O}_{4}$ composites. Journal of Applied Physics, 114 (5) (2013) 053902. http://dx.doi.org/10.1063/1.4817024.

24. L. John Berchmans, R. Kalai Selvan, C. O. Augustin, Evaluation of $\mathrm{Mg} 2+$-substituted $\mathrm{NiFe}_{2} \mathrm{O}_{4}$ as a green anode material, Materials Letters, 58 (12-13) (2004) 1928-1933. https://doi.org/10.1016/j.matlet.2003.12.008.

25. R. K. Hona , A. Huq, F. Ramezanipour, Electrical properties of the ordered oxygen-deficient perovskite $\mathrm{Ca}_{2} \mathrm{Fe}_{0.5} \mathrm{Ga}_{1.5} \mathrm{O}_{5}$. Ionics, 25(3) 1315-1321. https://doi.org/10.1007/s11581-018$\underline{2759-0 .}$.

26. H. M. J. Rietveld, A Profile Refinement Method for Nuclear and Magnetic Structure. Journal of Applied Crystallography,2 (2) (1969) 65-71. https://doi.org/10.2110/palo.2012.p12-116r.

27. S. J. Clark, M. D. Segallii, C. J. Pickardii, P. J. Hasnipiii, M .I. J. Probertiv, First principles methods using castep. Zeitschrift für Kristallographie, Journal of Physics D: Applied Physics,220 (2005) 567-570. https://doi.org/10.1088/0022-3727/47/32/322003.

28. A. K. Rajagopal, J. Callaway, Inhomogeneous Electron Gas, Physical Review B, 7 (5) (1973) 1912-1919. http://dx.doi.org/10.1103/PhysRevB.7.1912.

29. M. C. Payne, T. A. Arias, J. D. Joannopoulos, Iterative minimization techniques for ab initio total-energy calculations: molecular dynamics and conjugate gradients. Reviews of Modern Physics, 64 (4) (1992) 1045-1097. https://doi.org/10.1103/RevModPhys.64.1045.

30. W. Kohn, L. J. Sham, Self-Consistent Equations Including Exchange and Correlation Effects. $\begin{array}{lllll}\text { Physical } & \text { Review, } & 140 & \text { (4A) } & \text { (1965) A1133-A1138. }\end{array}$ http://dx.doi.org/10.1103/PhysRev.140.A1133.

31. J. P. Perdew, K. Burke, M. Ernzerhof, Generalized Gradient Approximation Made Simple Physical Review Letters, $77 \quad$ (18) (1996) 3865-3868. http://dx.doi.org/10.1103/PhysRevLett.77.3865.

32. J. P. Perdew, Unified Theory of Exchange and Correlation Beyond the Local Density Approximation, in Electronic Structure of Solids '91, pages 11-20, edited by P. Ziesche and H. Eschrig (Akademie Verlag, Berlin, 1991)

33. Y. Zhu, L. Peng, Z. Fang, C. Yan, X. Zhang, G. Yu, Structural Engineering of 2D Nanomaterials for Energy Storage and Catalysis, Advanced Materials, 30 (2018) 1706347. https://doi.org/10.1002/adma.201706347.

34. J. Liu, X.W. Liu, Two-Dimensional Nanoarchitectures for Lithium Storage. Advanced Materials, 24 (30) (2012) 4097-4111.http://dx.doi.org/10.1002/adma.201104993.

35. J. Liu, X.W. Liu, Two-Dimensional Nanoarchitectures for Lithium Storage. Advanced Materials, 24 (30) (2012) 4097-4111.http://dx.doi.org/10.1002/adma.201104993. 
36. C. N. R. Rao, H. S. S. Ramakrishna Matte, U. Maitra, Graphene Analogues of Inorganic Layered Materials. Angewandte Chemie International Edition, 52 (50) (2013) 13162-13185. http://dx.doi.org/10.1002/anie.201301548.

37. J. Wei, Y. Zhao, H. Li, et al. Hysteresis Analysis Based on the Ferroelectric Effect in Hybrid Perovskite Solar Cells. The Journal of Physical Chemistry Letters, 5 (21) (2014) 3937-3945. http://dx.doi.org/10.1021/jz502111u.

38. K. S. Cole, R.H. Cole, Dispersion and Absorption in Dielectrics I. Alternating Current Characteristics. The Journal of Chemical Physics, 9 (4) (1941) 341-351. https://doi.org/10.1063/1.1750906

39. J. Yang, J. S. Tse, First-principles molecular simulations of Li diffusion in solid electrolytes $\mathrm{Li}_{3} \mathrm{PS}_{4}$. Computational Materials Science, $107 \quad$ (2015): 134-138. http://dx.doi.org/10.1016/j.commatsci.2015.05.022 
Figures

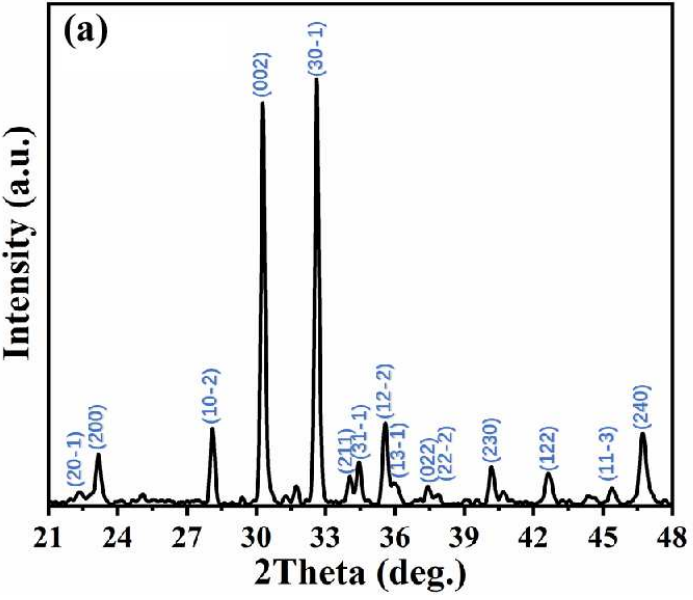

(c)

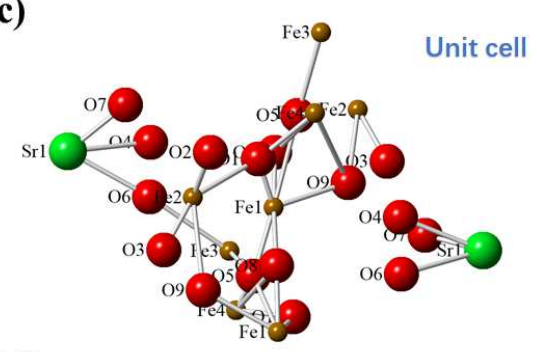

(d)

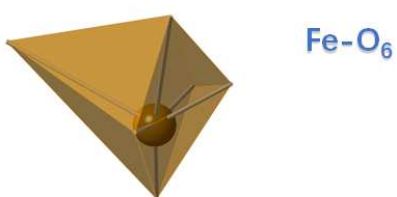

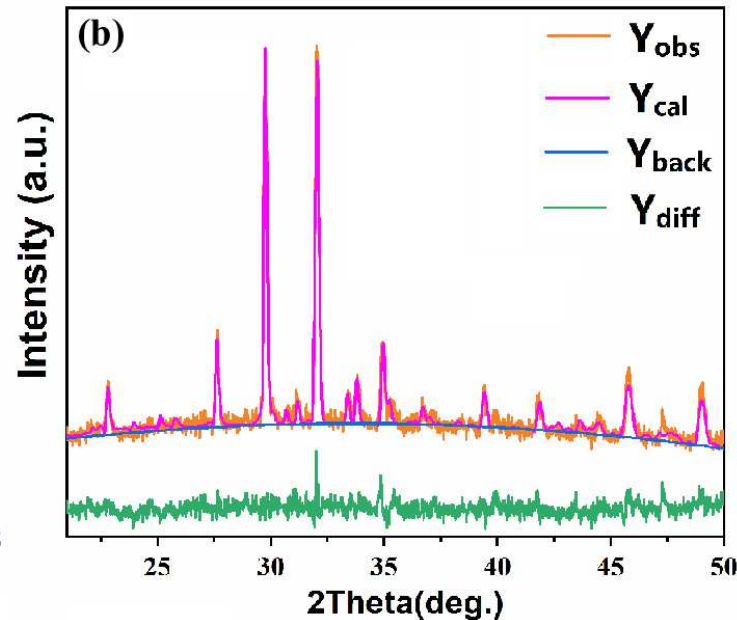

(e)
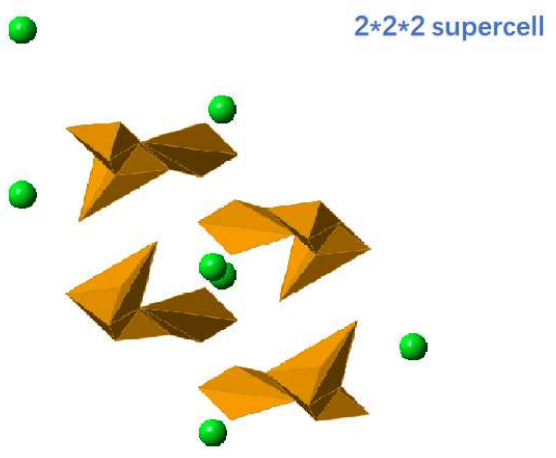

(0 10 ) direction

Fig. 1 (a) The XRD pattern of the $\mathrm{Sr}_{2} \mathrm{Fe}_{8} \mathrm{O}_{18}$ sample. Fig. 1 (b) (e) The graphical results of refinement and the detail of crystal structure of $\mathrm{Sr}_{2} \mathrm{Fe}_{8} \mathrm{O}_{18}$. (b) shows the graphical results of refinement; (c) (e) show the detail of crystal structure of $\mathrm{Sr}_{2} \mathrm{Fe}_{8} \mathrm{O}_{18}$ : (c) labeled unit cell of $\mathrm{Sr}_{2} \mathrm{Fe}_{8} \mathrm{O}_{18}$, (d) view of $\mathrm{FeO}_{6}$, (e) view of $2 * 2 * 2$ supercell in the direction of $(010)$. 


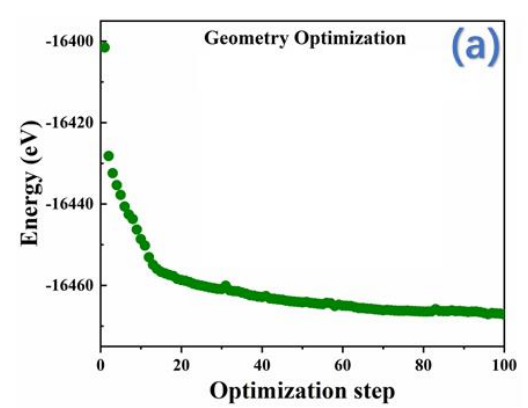

(d)
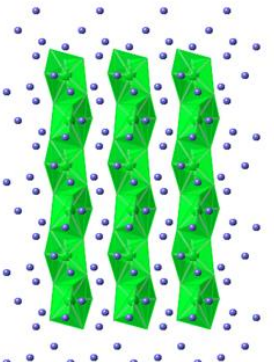

(100) $\mathrm{SrO}_{6}$ and $\mathrm{Fe}$

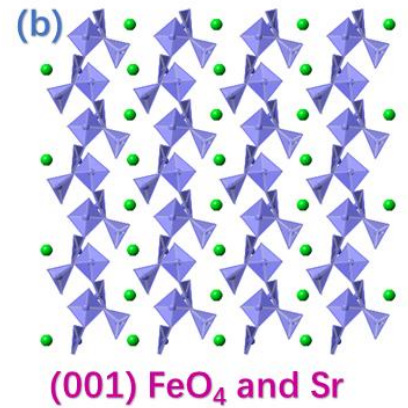

(e)

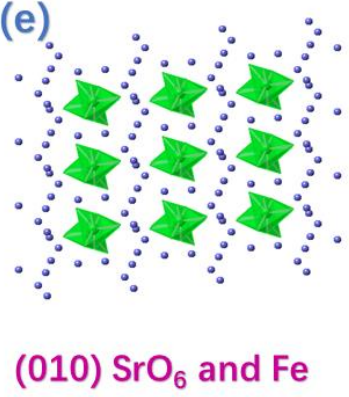

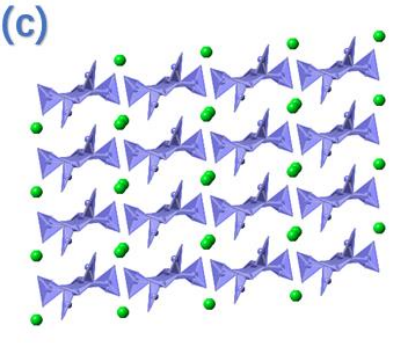

(010) $\mathrm{FeO}_{4}$ and $\mathrm{Sr}$

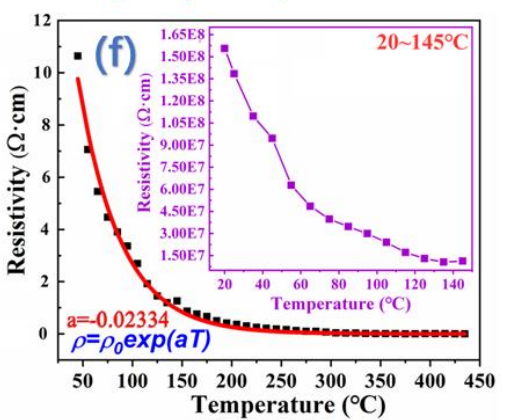

Fig. 2 The results of First principle calculation and resistivities of $\mathrm{Sr}_{2} \mathrm{Fe}_{8} \mathrm{O}_{18}$ in the temperature range of room temperature to $435^{\circ} \mathrm{C}$. (a) shows the energy optimizing results during the last time of geometry

optimization; (b) (e) shows the final crystal structure after geometry optimization: (b) and (c) $\mathrm{FeO}_{4}$ and $\mathrm{Sr}$ in the view of (001) and (010) direction, respectively, (d) and (e) $\mathrm{SrO}_{6}$ and $\mathrm{Fe}$ in the view of (100) and (010) direction, respectively; (f) the resistivities of $\mathrm{Sr}_{2} \mathrm{Fe}_{8} \mathrm{O}_{18}$ in the temperature range of room temperature to $435^{\circ} \mathrm{C}$, the inset of (f) shows the resistivities of $\mathrm{Sr}_{2} \mathrm{Fe}_{8} \mathrm{O}_{18}$ in the temperature range of 20 to $435^{\circ} \mathrm{C}$. 


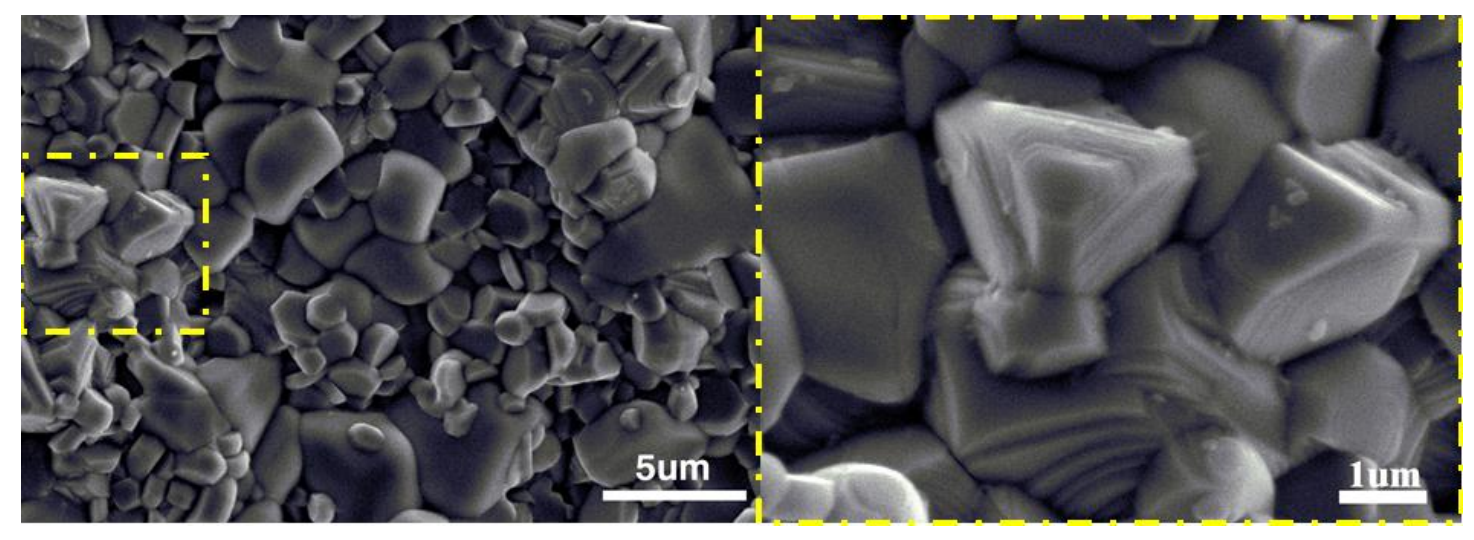

Fig. 3 The SEM photographs of the surfaces of the $\mathrm{Sr}_{2} \mathrm{Fe}_{8} \mathrm{O}_{18}$ samples. 

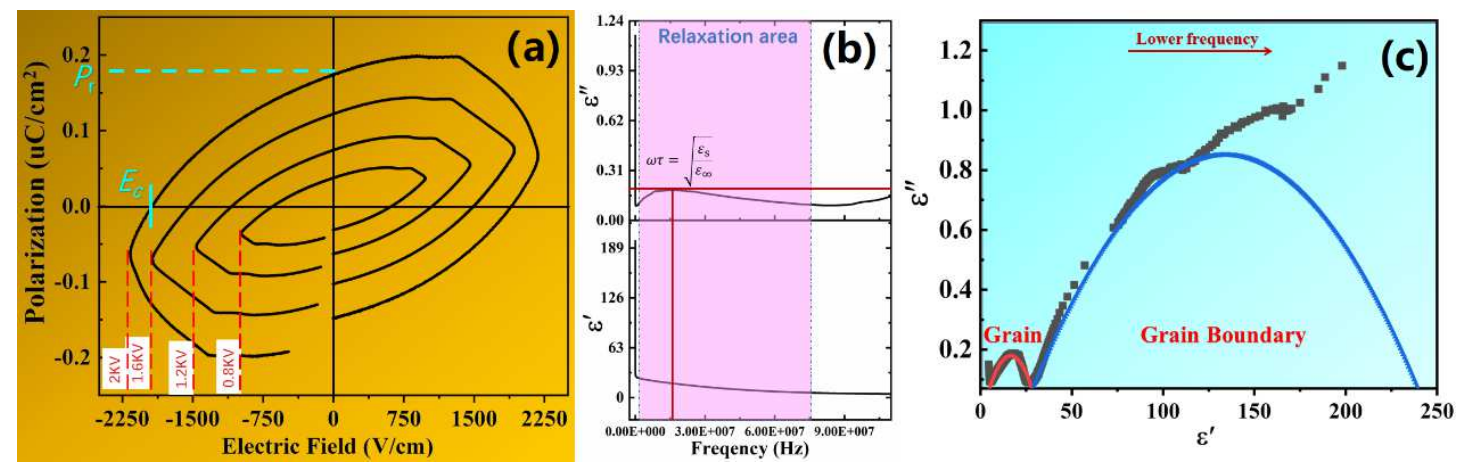

Fig. 4 The dielectric response of frequency, the Cole-Cole plot and ferroelectric property of $\mathrm{Sr}_{2} \mathrm{Fe}_{8} \mathrm{O}_{18}$.

(a) the dielectric response of frequency (form $40 \mathrm{~Hz}$ to $110 \mathrm{MHz}$ ) of $\mathrm{Sr}_{2} \mathrm{Fe}_{8} \mathrm{O}_{18}$; (b) the Cole-Cole plot from the data of (a); (c) the Polarization Electric field (P-E) hysteresis loops of the $\mathrm{Sr}_{2} \mathrm{Fe}_{8} \mathrm{O}_{18}$ samples tested at room temperature. 


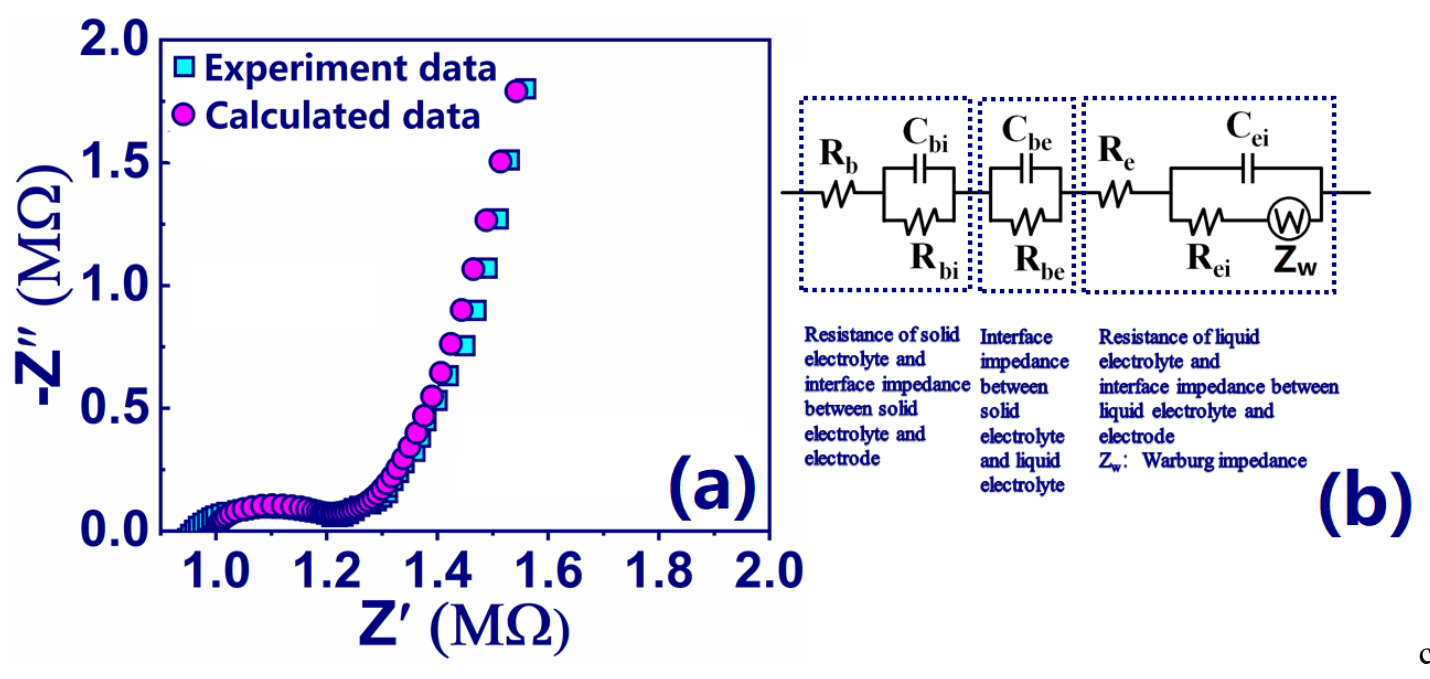

Fig. 5 The typical impedance plot obtained at room temperature for a $\mathrm{Sr}_{2} \mathrm{Fe}_{8} \mathrm{O}_{18}$ sample; (a) Nyquist

plot and the fitting curve; (b) equivalent circuit. $R_{\mathrm{b}}$ is the resistance of solid electrolyte; $V_{\text {oigt }}$ component composed by $C_{\mathrm{bi}}$ and $R_{\mathrm{bi}}$ is the interface impedance between solid electrolyte and electrode; $V_{\mathrm{oigt}}$ component composed by $C_{\text {be }}$ and $R_{\text {be }}$ is the interface impedance between solid electrolyte and liquid electrolyte; $R_{\mathrm{e}}$ is the resistance of liquid electrolyte; $V_{\text {oigt }}$ component composed by $C_{\mathrm{ei}}, R_{\mathrm{ei}}$ and $Z_{\mathrm{w}}$ is the interface impedance between liquid electrolyte and electrode; $Z_{\mathrm{w}}$ is the Warburg impedance. 

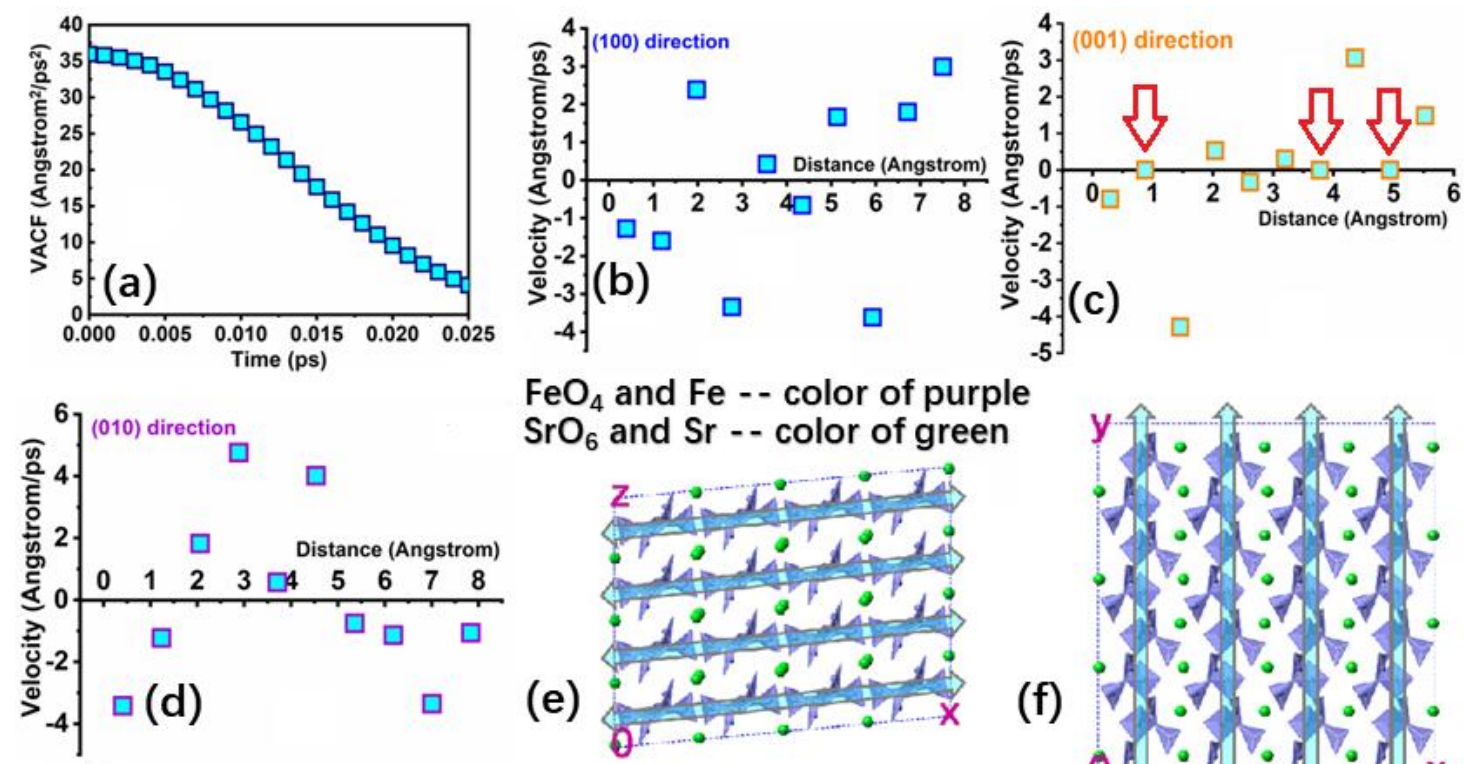

$\mathrm{FeO}_{4}$ and $\mathrm{Fe}--$ color of purple

$\mathrm{SrO}_{6}$ and $\mathrm{Sr}$-- color of green

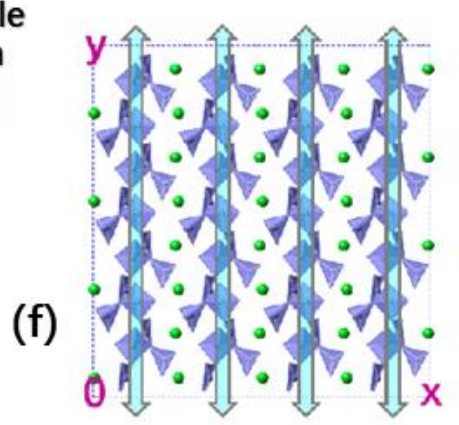

(g)

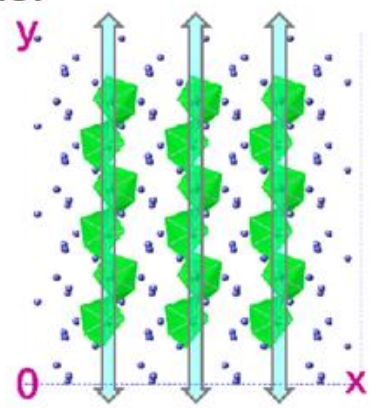

(e)

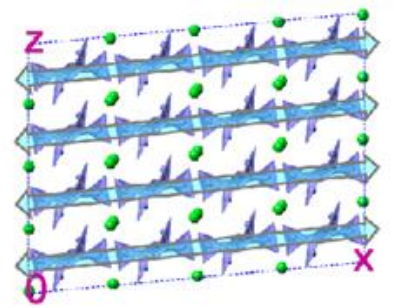

(h)

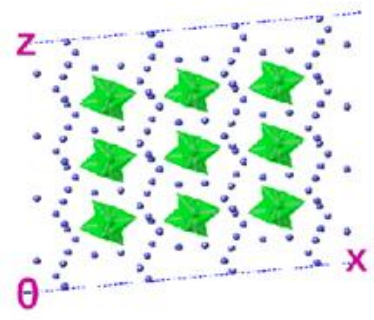

Fig. 6 Analysis of application on solid electrolytes for $\mathrm{Sr}_{2} \mathrm{Fe}_{8} \mathrm{O}_{18}$. (a) $\mathrm{VACF}$ (velocity autocorrelation function) curve; (b) Ion diffusion velocity on the (100) direction; (dc) Ion diffusion velocity on the (001) direction; (d) Ion diffusion velocity on (010) direction; (e) Fe ion diffusion path on $\mathrm{x}$ direction; (f) Fe ion diffusion path on y direction; (g) Sr ion diffusion path on y direction; (h) we intended to show that $\mathrm{Sr}$ ion don't have any diffusion path on $\mathrm{x}$ or $\mathrm{z}$ direction. 
Table 1 The structure parameters of the $\mathrm{Sr}_{2} \mathrm{Fe}_{8} \mathrm{O}_{18}$ and agreement factors from refinement.

\begin{tabular}{|c|c|c|c|c|c|c|c|c|c|c|}
\hline \multicolumn{7}{|c|}{ Cell parameters } & \multicolumn{4}{|c|}{ Agreement factors } \\
\hline$a(\AA)$ & $b(\AA ̊)$ & $c(\AA)$ & $\alpha\left({ }^{\circ}\right)$ & $\beta\left(\left(^{0}\right)\right.$ & $\gamma\left({ }^{0}\right)$ & $V_{\text {cell }}\left(\AA^{3}\right)$ & $R_{\mathrm{p}}$ & $R_{\mathrm{wp}}$ & $R_{\mathrm{e}}$ & $\mathrm{Chi}^{2}$ \\
\hline 8.4009 & 8.4623 & 6.4647 & 90 & 111.676 & 90 & 427.09 & 5.81 & 7.39 & 5.42 & 1.86 \\
\hline \multicolumn{11}{|c|}{ Structure } \\
\hline Atom & & $\mathbf{X}$ & & $\mathbf{Y}$ & & $\mathbf{Z}$ & & & & \\
\hline Sr1 & & 0.024 & & 0.723 & & -0.016 & & & & \\
\hline Fe1 & & 0.522 & & 0.984 & & 0.328 & & & & \\
\hline $\mathrm{Fe} 2$ & & -0.145 & & 0.536 & & 0.520 & & & & \\
\hline $\mathrm{Fe} 3$ & & 0.403 & & 0.505 & & 0.014 & & & & \\
\hline $\mathrm{Fe} 4$ & & 0.454 & & 0.789 & & 0.146 & & & & \\
\hline 01 & & 0.383 & & 0.873 & & 0.404 & & & & \\
\hline $\mathbf{O 2}$ & & -0.064 & & 0.484 & & -0.134 & & & & \\
\hline $\mathbf{O 3}$ & & -0.093 & & 0.753 & & -0.473 & & & & \\
\hline O4 & & 0.313 & & 0.654 & & -0.024 & & & & \\
\hline 05 & & 0.475 & & 0.704 & & 0.319 & & & & \\
\hline O6 & & 0.302 & & 0.864 & & -0.034 & & & & \\
\hline 07 & & 0.106 & & 0.627 & & -0.249 & & & & \\
\hline 08 & & 0.543 & & 0.755 & & 0.567 & & & & \\
\hline O9 & & -0.242 & & 0.863 & & -0.493 & & & & \\
\hline
\end{tabular}


Figures

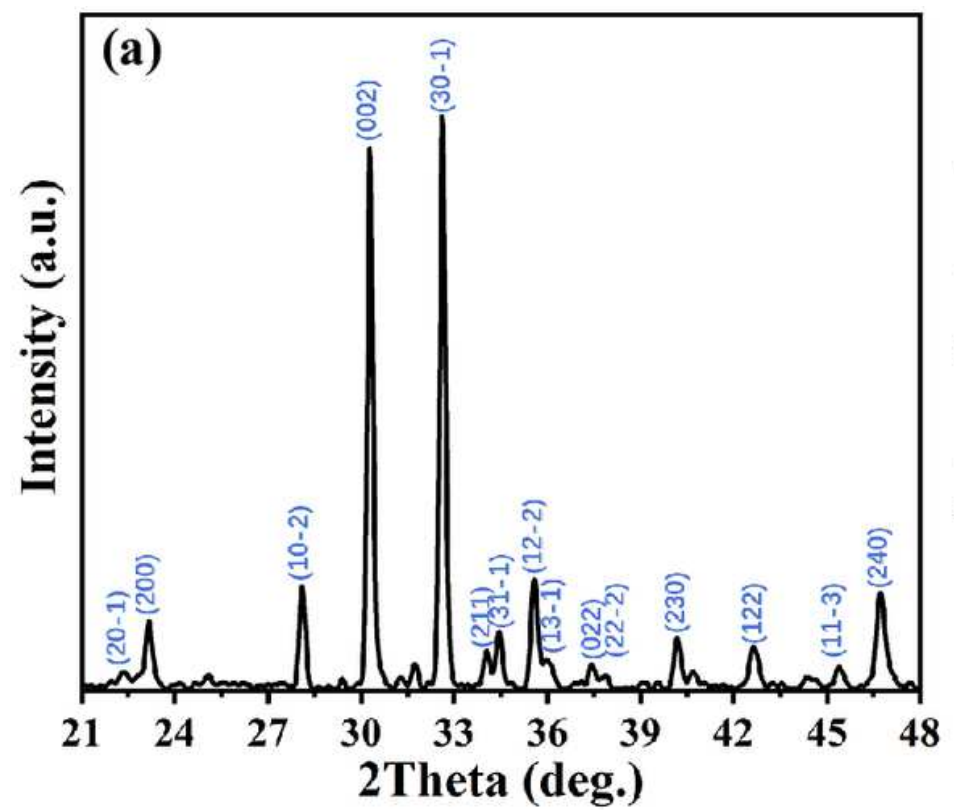

(c)

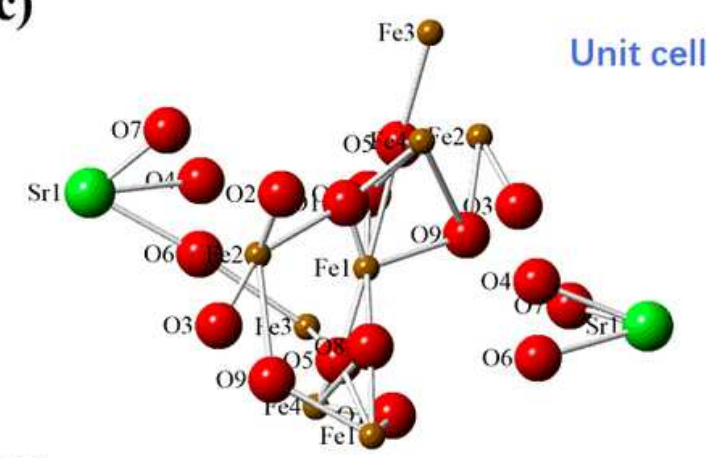

(d)

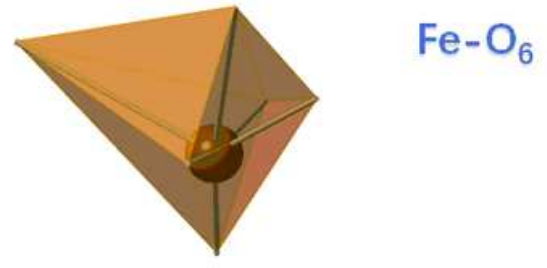

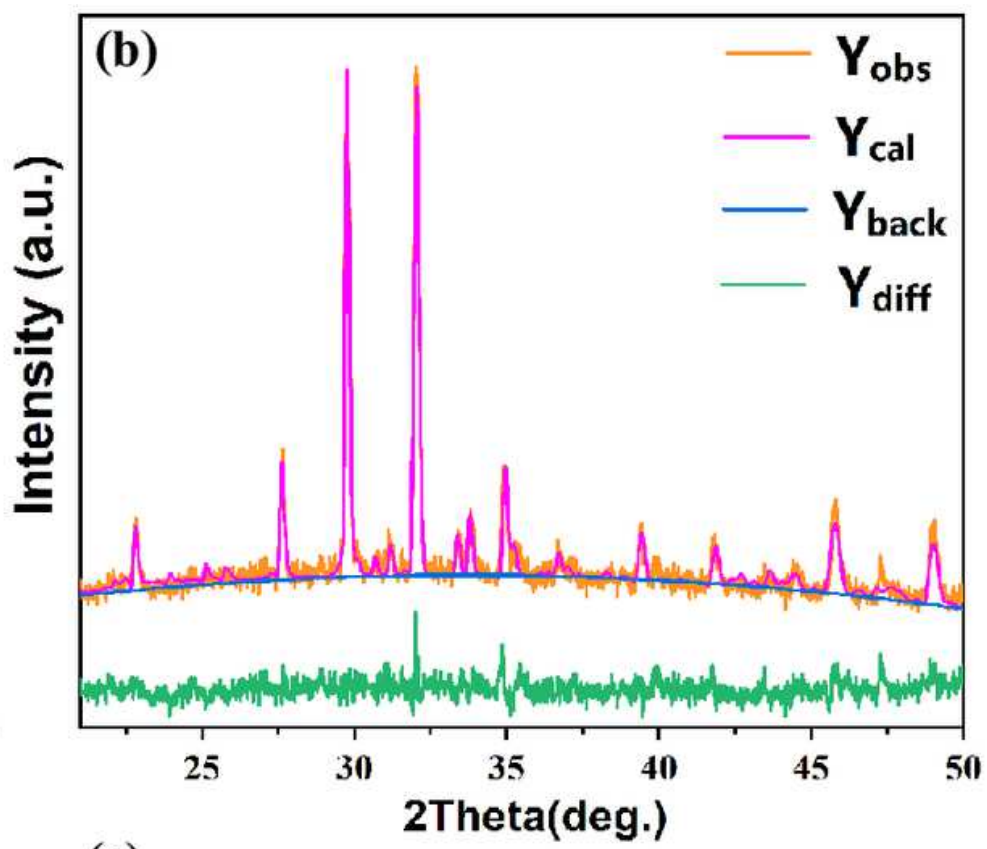

(e)
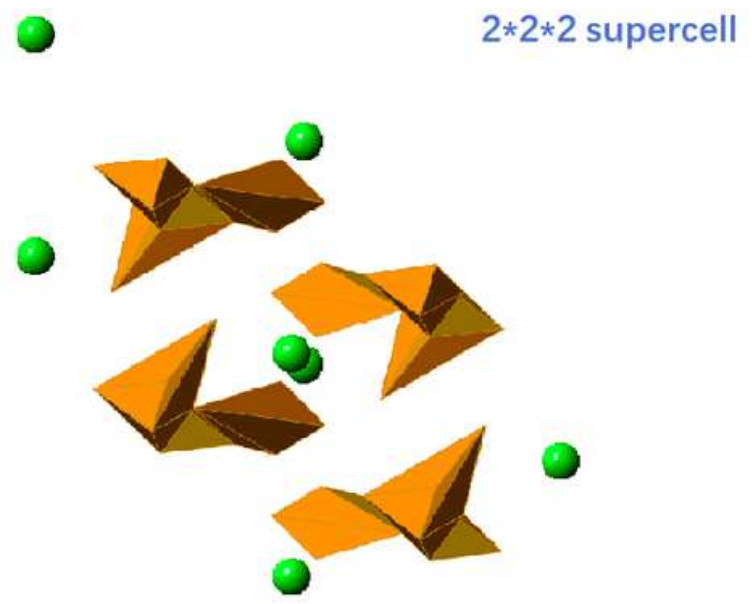

(0 10 ) direction

\section{Figure 1}

(a) The XRD pattern of the Sr2Fe8018 sample. Fig. 1 (b) (e) The graphical results of refinement and the detail of crystal structure of Sr2Fe8018. (b) shows the graphical results of refinement; (c) (e) show the detail of crystal structure of Sr2Fe8018: (c) labeled unit cell of Sr2Fe8018, (d) view of FeO6, (e) view of $2 \star 2 \star 2$ supercell in the direction of $(010)$. 

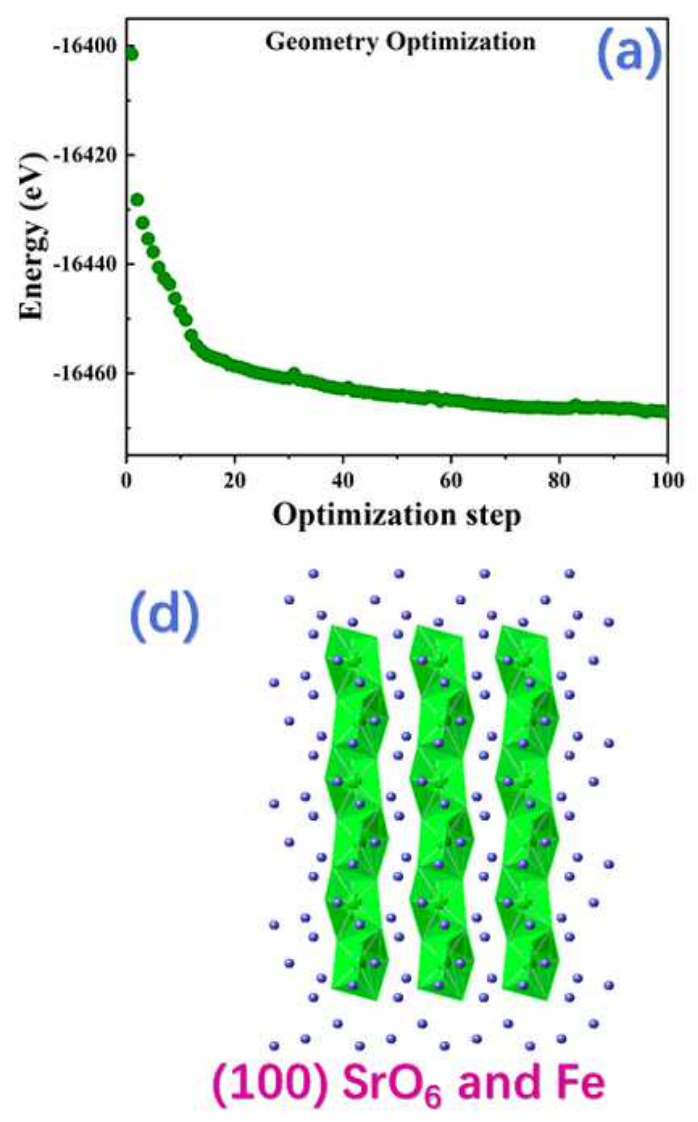
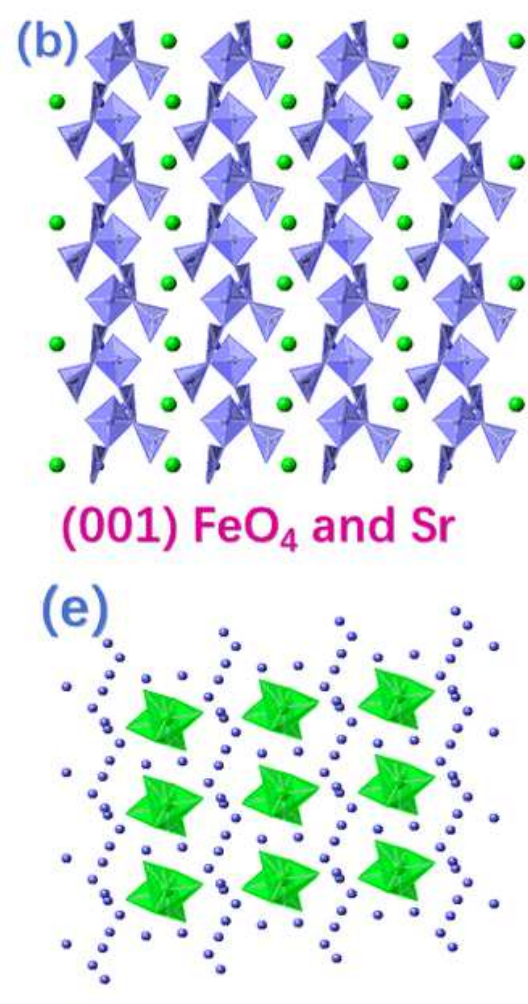

(010) $\mathrm{SrO}_{6}$ and $\mathrm{Fe}$ (c)

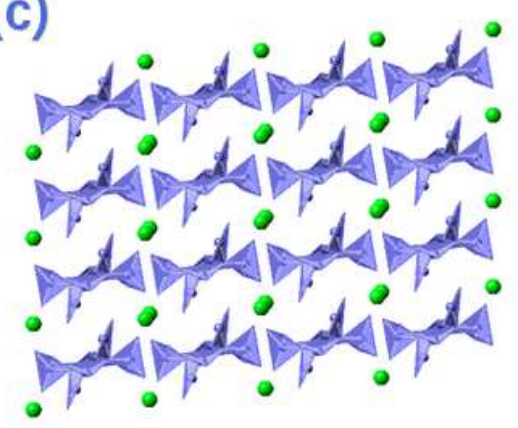

(010) $\mathrm{FeO}_{4}$ and $\mathrm{Sr}$

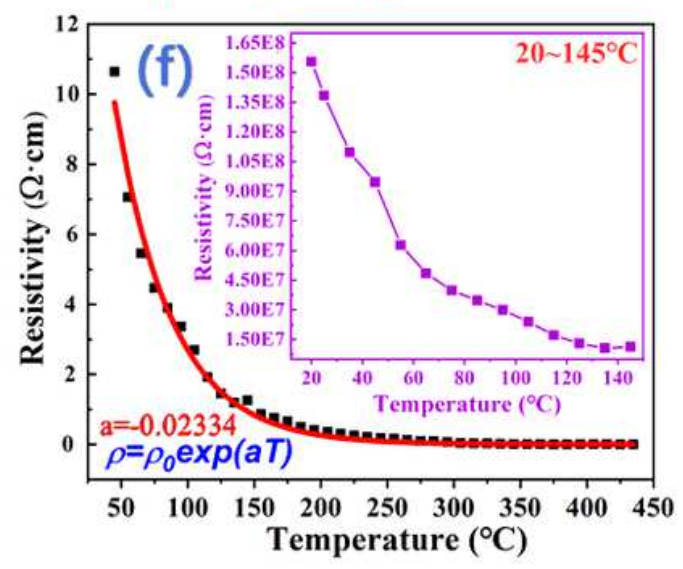

Figure 2

The results of First principle calculation and resistivities of Sr2Fe8018 in the temperature range of room temperature to $435^{\circ} \mathrm{C}$. (a) shows the energy optimizing results during the last time of geometry optimization; (b) (e) shows the final crystal structure after geometry optimization: (b) and (c) FeO4 and Sr in the view of (001) and (010) direction, respectively, (d) and (e) SrO6 and Fe in the view of (100) and (010) direction, respectively; ( $f$ ) the resistivities of Sr2Fe8018 in the temperature range of room temperature to $435^{\circ} \mathrm{C}$, the inset of (f) shows the resistivities of Sr2Fe8018 in the temperature range of 20 to $435^{\circ} \mathrm{C}$.

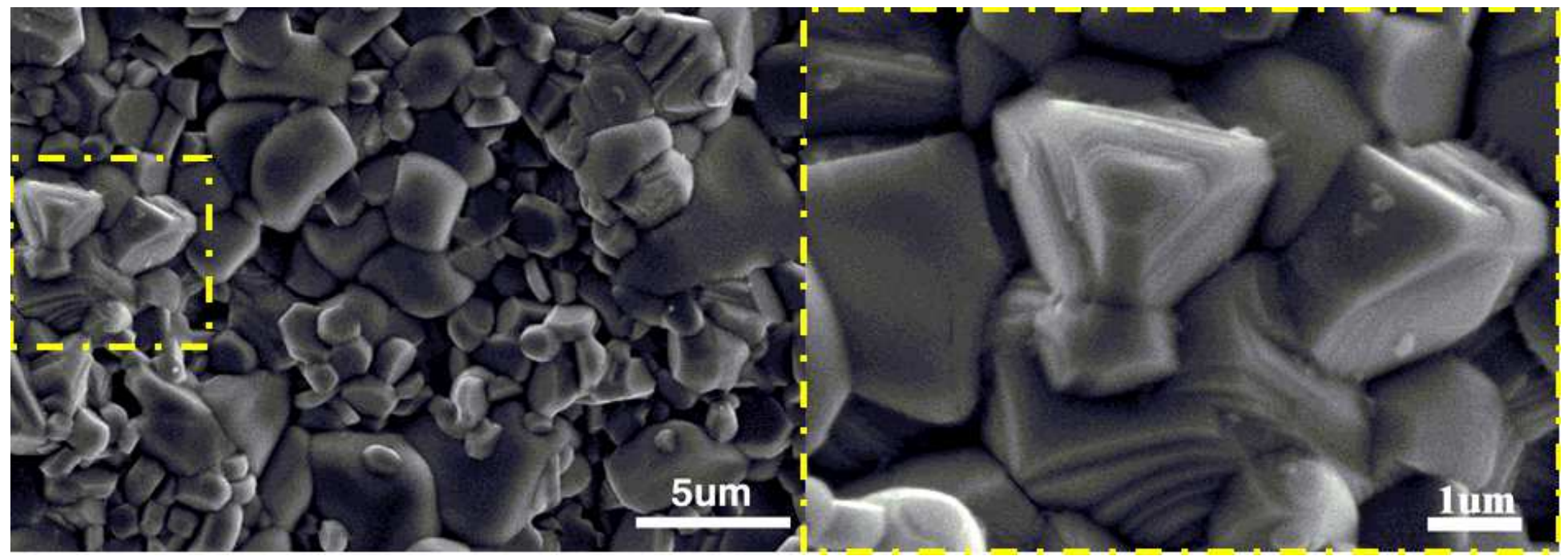


The SEM photographs of the surfaces of the Sr2Fe8018 samples.
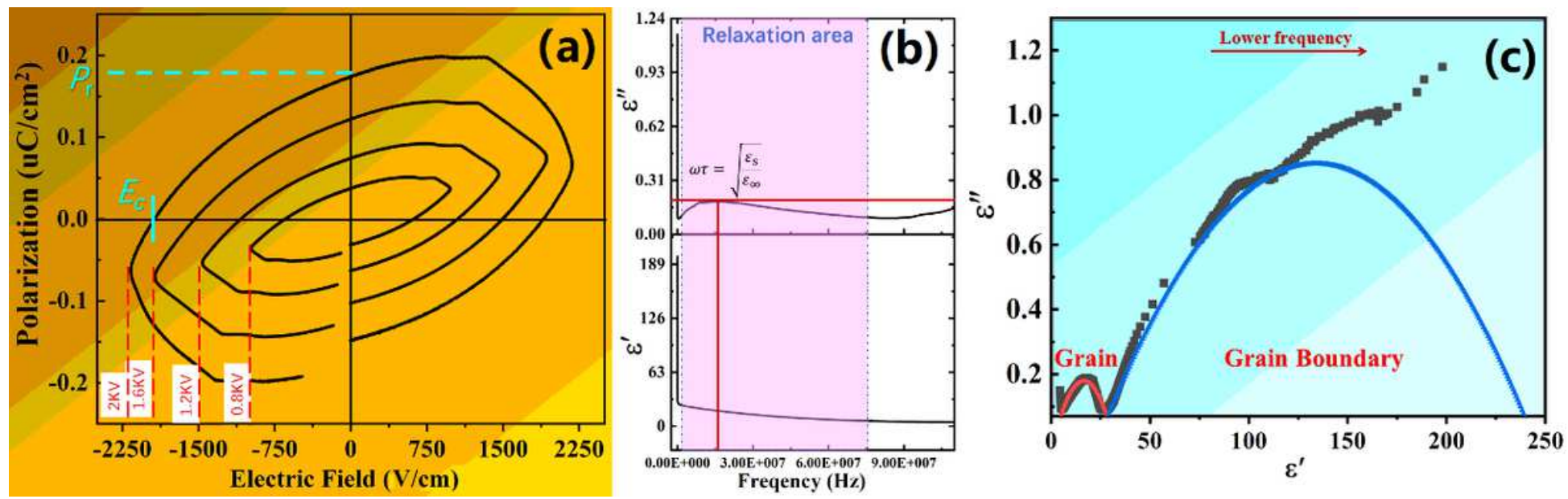

Figure 4

The dielectric response of frequency, the Cole-Cole plot and ferroelectric property of Sr2Fe8018. (a) the dielectric response of frequency (form $40 \mathrm{~Hz}$ to $110 \mathrm{MHz}$ ) of Sr2Fe8018; (b) the Cole-Cole plot from the data of (a); (c) the Polarization Electric field (P-E) hysteresis loops of the Sr2Fe8018 samples tested at room temperature.

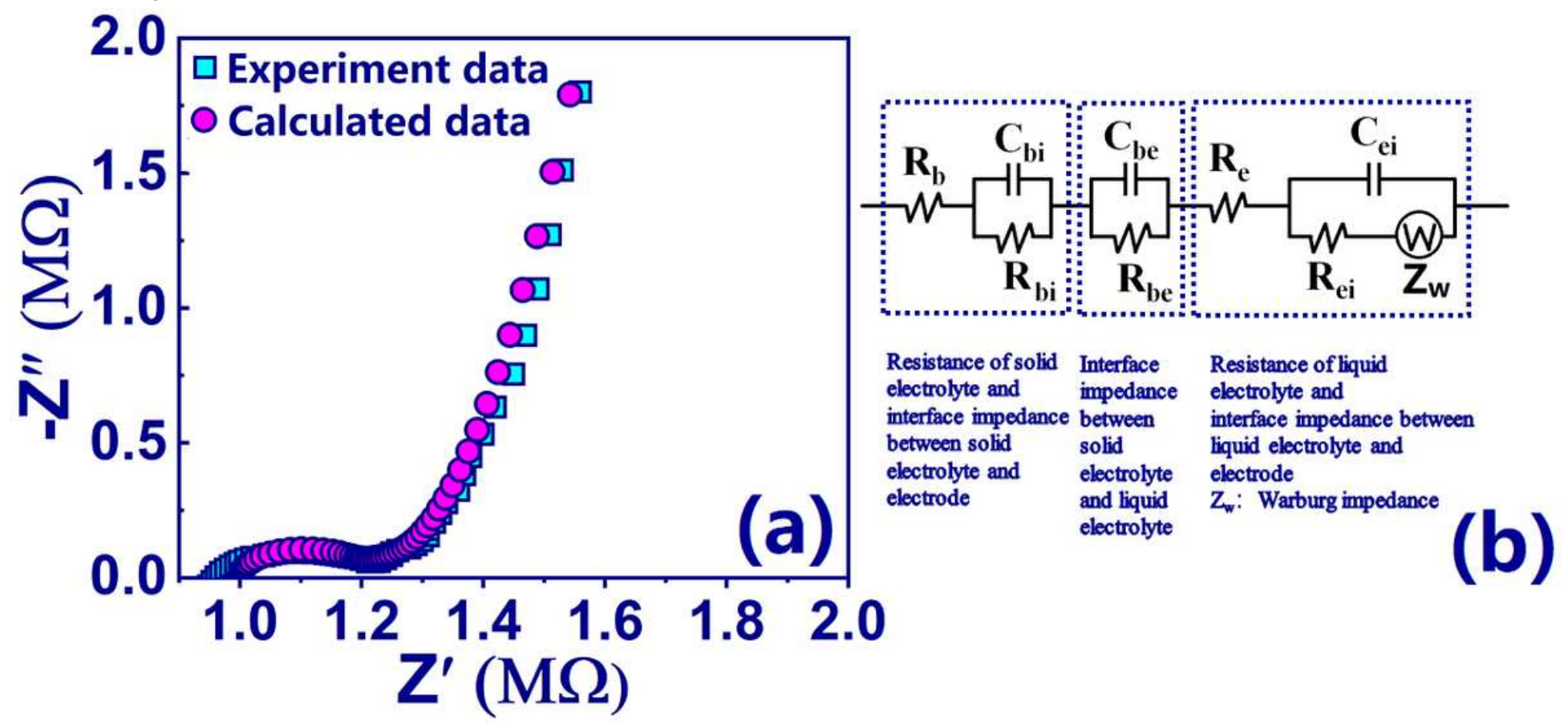

Figure 5

The typical impedance plot obtained at room temperature for a Sr2Fe8018 sample; (a) Nyquist plot and the fitting curve; (b) equivalent circuit. $\mathrm{Rb}$ is the resistance of solid electrolyte; Voigt component composed by $\mathrm{Cbi}$ and $\mathrm{Rbi}$ is the interface impedance between solid electrolyte and electrode; Voigt component composed by $\mathrm{Cbe}$ and $\mathrm{Rbe}$ is the interface impedance between solid electrolyte and liquid 
electrolyte; Re is the resistance of liquid electrolyte; Voigt component composed by Cei, Rei and Zw is the interface impedance between liquid electrolyte and electrode; Zw is the Warburg impedance.
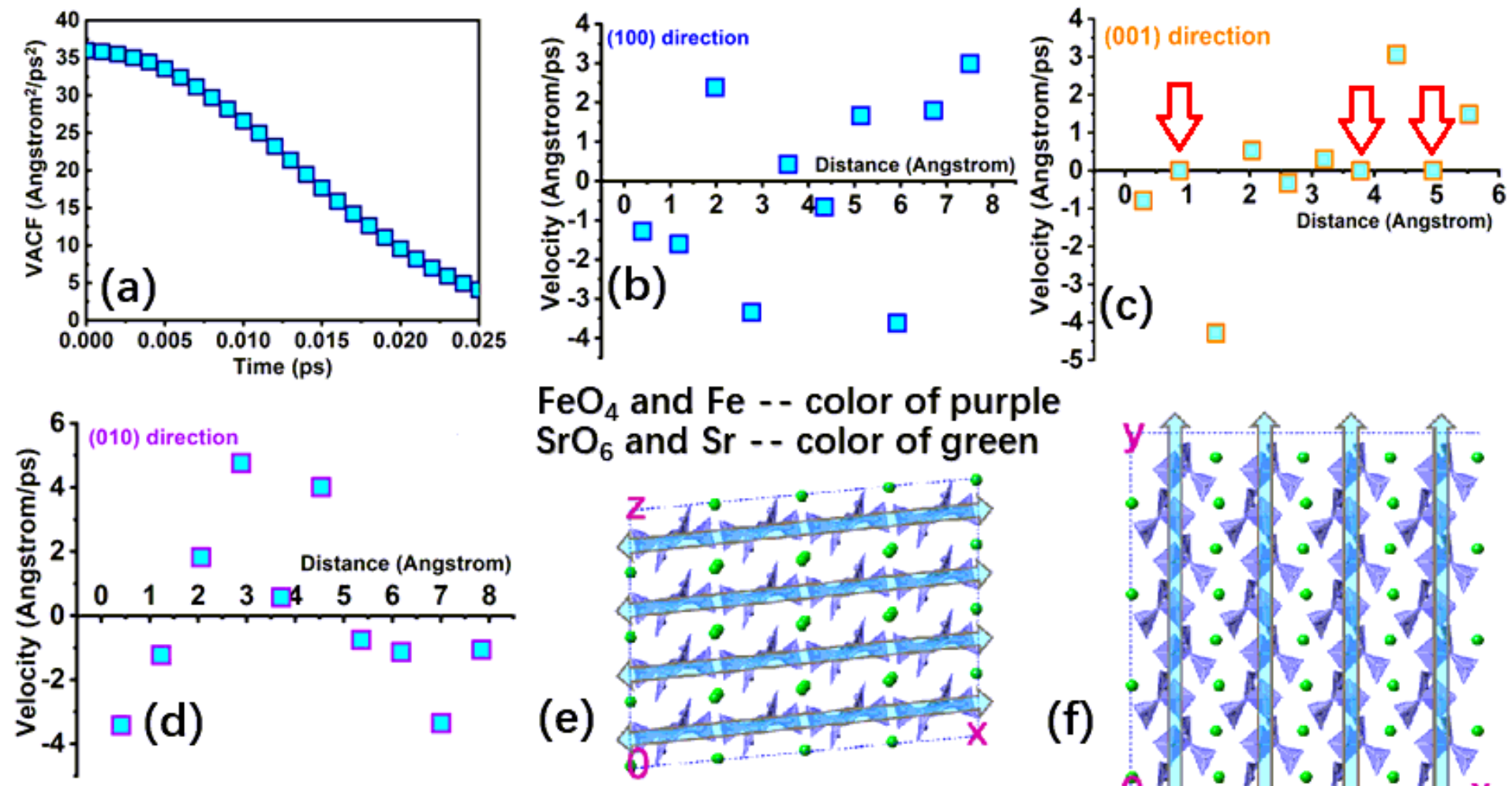

$\mathrm{FeO}_{4}$ and $\mathrm{Fe}$-- color of purple $\mathrm{SrO}_{6}$ and $\mathrm{Sr}$-- color of green

(g)

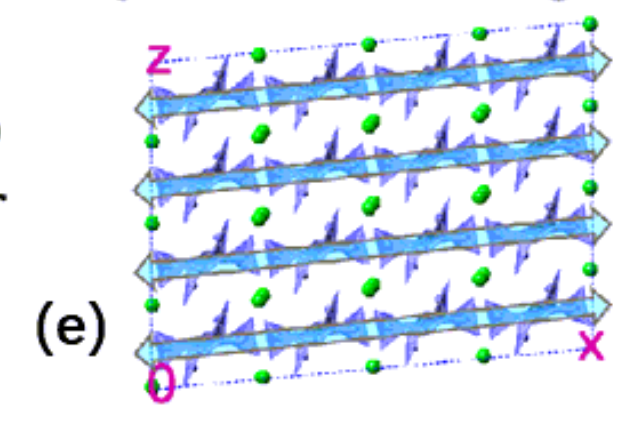

(f)

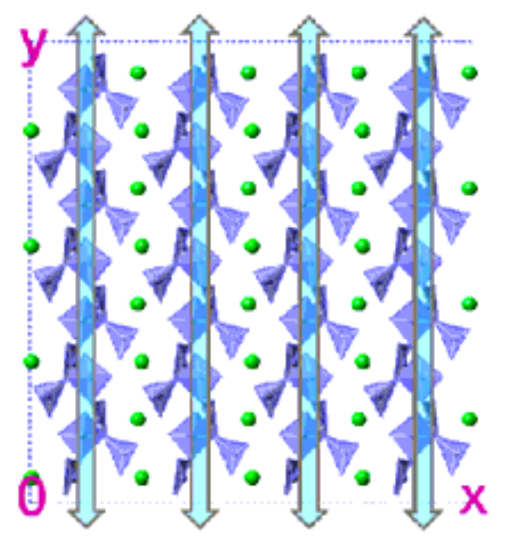

(h)
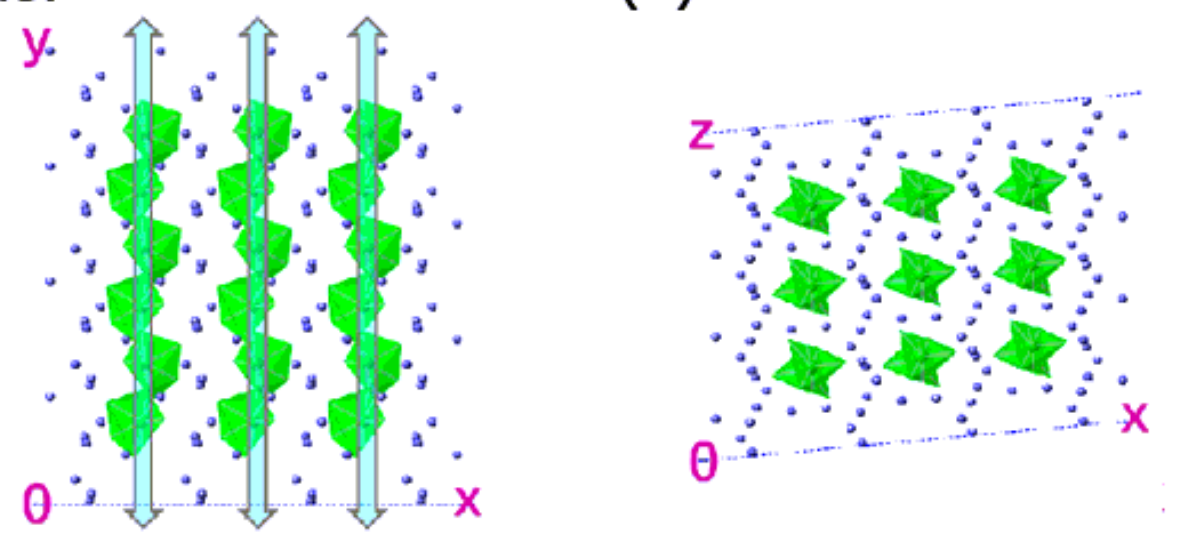

Figure 6

Analysis of application on solid electrolytes for Sr2Fe8018. (a) VACF (velocity autocorrelation function) curve; (b) Ion diffusion velocity on the (100) direction; (dc) Ion diffusion velocity on the (001) direction; (d) Ion diffusion velocity on (010) direction; (e) Fe ion diffusion path on $x$ direction; (f) Fe ion diffusion path on y direction; (g) Sr ion diffusion path on y direction; (h) we intended to show that Sr ion don't have any diffusion path on $\mathrm{x}$ or $\mathrm{z}$ direction. 